\title{
Design and analysis of information model hotel complex
}

\author{
Nikolai Garyaev ${ }^{1, *}$ \\ ${ }^{1}$ Moscow State University of Civil Engineering, 129337 Yaroslavskoe shosse 26, Moscow, Russia
}

\begin{abstract}
The article analyzes the innovation in 3D modeling and development of process design approaches based on visualization of information technology and computer-aided design systems. The problems arising in the modern design and the approach to address them.
\end{abstract}

\section{Introduction}

Modern computer technologies are being actively implemented in various spheres of human activity, their use becomes an essential condition for successful operation and competitiveness of today's market. In this regard, modern hotel - this is not just a place away from home, and the night, and a complex set, which includes a variety of functions, such as living space, food areas, recreational facilities, technical facilities and service infrastructure [1-14].

On this basis, the development of a hotel complex in front of designers and architects, a number of topical issues, such as:

- Wide range of realization of hotels, they create near airports, in remote from populated areas settlements where people could enjoy nature and get away from the bustle of the city (ekooteli) hotels short stays - Waiting plane or train, to negotiate and so on.

- Proper zoning and the creation of technological schemes of the hotel, in order to reduce the intersection of personnel and guests stream for a comfortable stay of the latter. The project must take into account the different nuances and parameters on which will continue to depend on the profitability and the successful functioning of the entire complex.

- The need for design and construction of building structures of complex geometries without seeing the final result - it's a big risk. In this connection there is need to prepare drawings of virtualization and the adjacent landscaped grounds in an easy, understandable and reflects the basic properties of the form.

- The original idea of the future of the hotel should be interesting and attractive for the guest.

\footnotetext{
* Corresponding author: garyaev@mail.ru
} 
On the relevance of this research work has affected the company «VFM Leonardo Hotel EBusiness». The key objective of the monitoring was to identify and analyze what hospitality professionals are doing and plan to do to increase online - the presence of the hotel (hotels), increasing the number of visitors (1 diag.). Research has shown hospitality tours (combination of 3d-panoramas, photo galleries, videos and animations): 66\%, advertising and demonstration video: $62 \% 3 \mathrm{~d}$-panoramas (360 ${ }^{\circ}$ panoramas): $49 \%$, search landing pages 36\%, Images and Photos reflecting the life style: $34 \%$, interactive brochures: $34 \%$, therefore, the most effective is a combination of rich media tactics and tactics based on social media. In particular, the connection of the high-quality visual content like video and visual tours hotels (with circular 3d-panoramas, photographs, etc.) with user reviews, ratings and rankings.

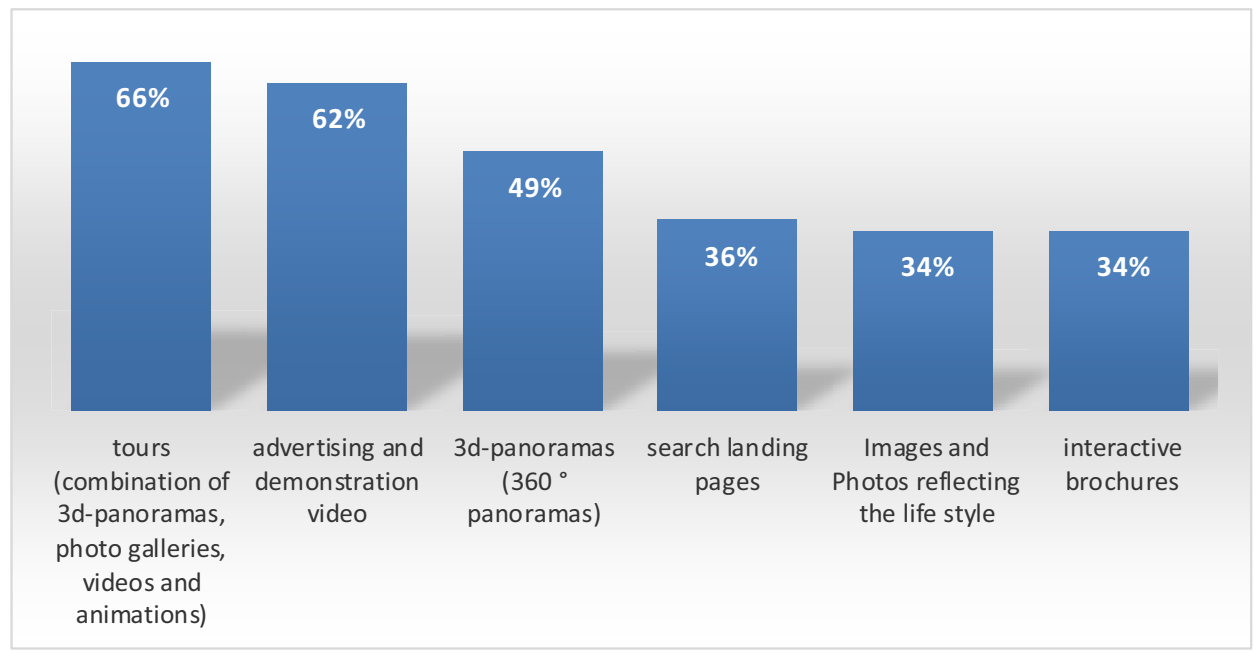

Fig. 1. The most effective multimedia according to «VFM Leonardo Hotel E-Business 2010".

\section{Development}

Having considered the above-mentioned problems, realizing the urgency of their solution, the problem arises - to analyze innovation in the 3D modeling and design using information visualization and computer-aided design technology based on information model property.

To solve this problem, you must:

1. Create a project exhaustive information architectural model of the hotel complex, with the aim of providing accessible information about the object, provided that the threedimensional environment allows you to navigate through a virtual project in real time (it shows everything at once: the building materials used, equipment, interior fittings, including transport accessibility, landscaping level, significant specific points, d.) the interaction with the surrounding objects, and so on.

2. Development of recommendations on the use of new technologies for the design of the hotel complex.

It is well known: it is better to see once than hear a hundred times. This adage true for the modern construction industry, when to replace the traditional (2D) projection technology comes the 3D-modeling (see. Fig. 1) (a), (b), and then the building information modeling (the BIM). The project, created with the help of information modeling, not simply provides increased visibility of the results of and the most accurate reflection of the fruits of the architectural and technical imagination in a format close to reality, but creates a 
complete data base on BLM (Building Lifecycle Management) lifecycle management of buildings, and even longer. Data contained in it may be changed, supplemented, replaced by reproducing the current condition of the building.

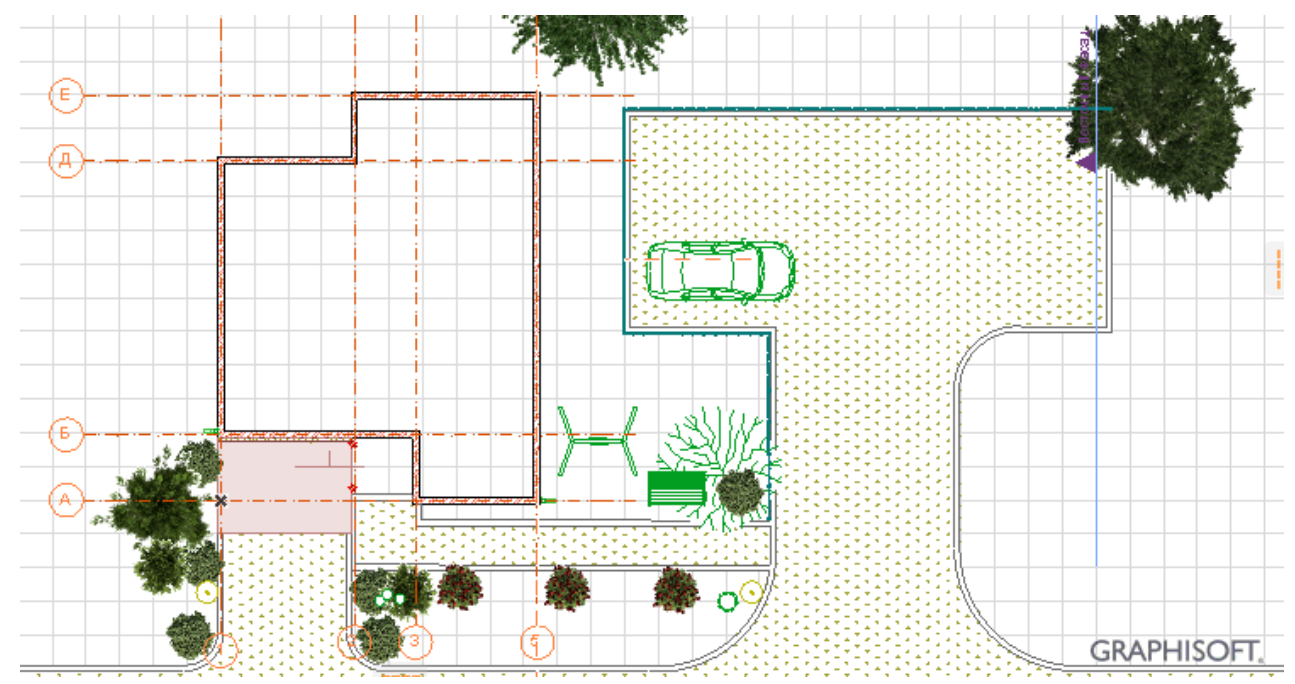

Fig. 2. (a) Detail of plan of the hotel complex in ArchiCAD.

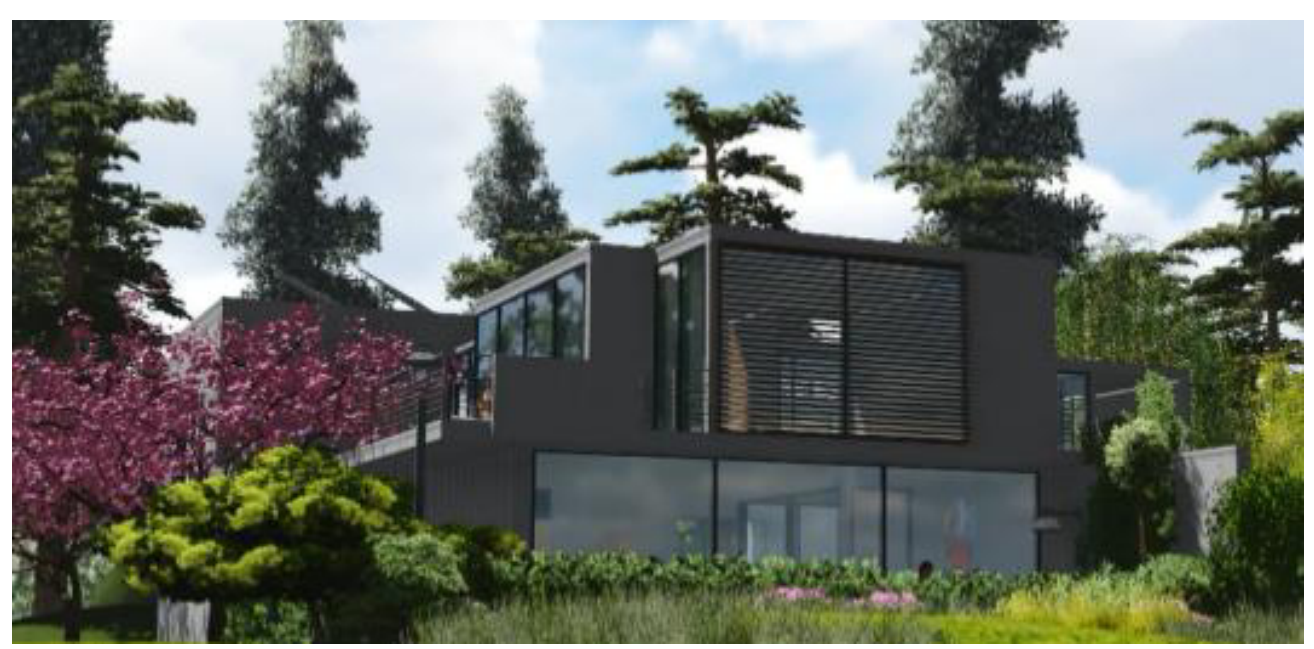

Fig. 3. (b) a facility Virtualization.

So, how, work is underway to establish the information model.

First developed some blocks (family) - the primary elements of design that correspond to the construction products (windows, doors, floor slabs, etc.) and elements of equipment (heating and lighting, elevators, etc.) and much more that is directly related to the building, but produced outside the construction site and the construction of the object is not divided into parts.

The second stage - modeling that is created on the construction site. This foundation, walls, roofs, curtain walls, and more. This assumes the widespread use of pre-existing 
elements, such as mounting or framing components in the formation of curtain wall of the building.

This division into stages (first and second) when building information model is rather conditional - you can, for example, to insert a door in the simulated object, and then, again appeared reasons to change them, and the project will be assigned has already changed the door.

Built experts information model of projected object then becomes the foundation and actively used to create working documents of all types of development and production of building structures and components, facility equipment, economic calculations, the organization of the construction of the building itself. It also provides a solution to the technical error in the project, due to quality of coordination between departments and merge all the partitions in a single space model.

However, all the experts are also aware that, in spite of the high accuracy of the information models and the quality of computer software documentation for construction, all this will not make sense without taking into account the fact that a successful construction business, first and foremost, should be cost-effective. Namely, should always be money to build, and dating should always be sold in the future to function correctly.

To these obvious axioms become a reality, steps to attract investors and selling space in the new building begins long before the completion of his design. Ideally, they should already be completed before the completion of the design.

Thorough work with potential investors at the design stage involves the implementation of a minimum of three mandatory conditions, without which it is impossible to implement the funding:

1. The customer should be as clear picture of all the components of the building, its equipment, organization of construction, etc.

2. It should be possible promptly make changes to the project, taking into account the constantly emerging new customer requirements and without altering designated for all time.

3. At each adjustment of the project, each new version should be able to quickly retrieve its economic characteristics and all the necessary technical information.

The construction industry of developed countries, Investor has long been a high priority, and in this line of business building information modeling, and has established itself well, it was simply irreplaceable at the present rate and volume of construction.

As for individual housing construction, in particular hotels, here BIM efficiency is also very convincing. After all, the buyer of the building (or individual developers) usually takes care of the cost savings. This is organized through information modeling as optimization of the cost of building and construction of proper organization. This BIM also allows the well to predict the subsequent operating costs of the building, which in most cases can be crucial in the construction or operation of the construction site.

Maintenance and repair of buildings - one of the most important and highly costly activities of daily living, in which information modeling plays an important role. For example, the management company will be convenient to know in advance how much and where the bulbs should be replaced as paint or water pipes necessary for the overhaul of the building, how much it will cost replacement of equipment, furniture, construction and architectural features, where to find them at a better price and in what time You can carry out these works.

Thus, when designing the question as any man, from the architect and finishing manager of the hotel, I could see the information model in an understandable and clear as much as possible.

And realize this is possible, for example, with the help of such software as Graphisoft BIMx for ArchiCAD. This tool for architects, includes modern methods of communication 
and presentation projects. Any user of the program can now literally plunge into the project: a three-dimensional environment, without having special knowledge. 3D navigation area allows you to perform real-time 3D virtual tour of the architectural design. This can include stereootobrazheniya modes, gravity, and free flight, control layers, differentiate openings and solid objects. The program features the ability to save the passage of the building as an independent exe-file and its further demonstration without having to install additional software and a long tiring training.

Also, any element models can be filed data relating to him a passport for the equipment, material, dimensions, manufacturer and other information. There is no need to look for it all the folders on the disc, a bookshelf, closet, etc. A user can open the model and get from it all the necessary information in a structured way and the cost of the minimum time.

The program provides the user with information about the object in a wide range of species (plans, sections, presentation files, rendering and animation models, 3D models, and the like) technologically suitable for further processing by computer or other means.

\section{Conclusion}

Thus, we can conclude that the information model for today - is a kind of database that contains a 3D model of the passport facilities, library records and other information on the building project in a structured and interconnected form. Of course, the introduction of an information model implies the inclusion of expensive BIM-tool, but its use is quite reasonable and effective, as it allows you to perform and provide the following:

- Visualization, simulation and testing technology of labor-intensive construction and installation works;

- Eliminate time-space error due to visualization and analysis of construction and installation;

- Planning for the implementation of resources;

- Modeling and visualization of the processes of repair (assembly, disassembly, etc.);

- Creating a reference database with visual organization operative approach with a single access point provided in the executive form of the three-dimensional model, etc. This information model contains: all engineering and other data about the object: the information on the operation and maintenance, design documentation, results of installation and set-up data and the pre-launch tests and stuff;

- Building on the basis of them a single information space for coordination of interactions among the various units;

- Creating an information model based on 3D or panorama tour for visually spectacular and reasonable presentation of the institutions as partners and customers.

\section{References}

1. V.V. Garyaeva, N.A. Garyaev, Computing in Civil and Building Engineering Proceedings 2014 International Conference, 1336-1343 (2014)

2. P.N. Garyaev, Computing in Civil and Building Engineering Proceedings 2014 International Conference, 1618-1625 (2014)

3. N.A. Garyaev, Computing in Civil and Building Engineering Proceedings 2014 International Conference, 1578-1585 (2014)

4. V. Goryunov, I. Zayats, T. Konjkova, V. Murgul, Procedia Engineering, 117, 825-831 (2015)

5. I. Yamshanov, V. Goryunov, V. Murgul, Procedia Engineering, 117, 675-684 (2015)

6. V. Murgul, N. Vatin, I. Zayats, Procedia Engineering, 117, 824-829 (2015) 
7. G. Radovic, V. Murgul, N. Vatin, Applied Mechanics and Materials, 641-642, 634638 (2014)

8. R. Alihodzic, V. Murgul, N. Vatin, Applied Mechanics and Materials, 680, 494-498 (2014)

9. B. Hardin, D. McCool, BIM and Construction Management: Proven Tools, Methods, and Workflows. 2nd Edition (Indianapolis, 2015)

10. M. Hergunsel Benefits of building information modeling for construction managers and BIM based scheduling (Master's Thesis, Worcester, 2011)

11. M. Day, AEC Magazine, 1 (47), 16-19 (2013)

12. L. Allen AutoCAD Professional Tips and Technique (San-Rafael, 2014)

13. A. V. Petelin 3D-modyelirovaniye v SketchUp 2015 in 2 volumes (St. Petersburg, 2015)

14. J. Vandezande, P. Read, E. Krygiel Autodesk Revit Architecture 2013: Autodesk Official Training Guide (San-Rafael, 2015) 